\title{
Colonization, population dynamics, predatory behaviour and cannibalism in Heterocypris incongruens (Crustacea: Ostracoda)
}

\author{
Valeria ROSSI*, Giorgio BENASSI, Francesco BELLETTI and Paolo MENOZZI \\ Department of Environmental Sciences, University of Parma, Viale G.P. Usberti 11/A, I-43100, Parma, Italy \\ *e-mail corresponding author: valeria.rossi@unipr.it
}

\begin{abstract}
We followed the artificial colonization of a temporary pond in Northern Italy by the freshwater ostracod Heterocypris incongruens. The species had not been found in the pond in previous years. In May 2009 we released five laboratory reared, genetically identical, parthenogenetic females and observed the population during colonization and growth until desiccation (MayJuly 2009) and two subsequent hydro-periods (February-March and May-July 2010). High population density was always reached in few weeks, although in late winter 2010 no ovigerous female was observed and in spring 2010 the population was recruited only from resting eggs. In all three hydro-periods swarms formed every day and could be easily seen near the border of the pond to the eye around the median time of the sun path. In laboratory observations, individuals sampled from the swarm forming population showed predatory behaviour: H. incongruens attack, kill and consume live, actively self-defending organisms (Chironomid and mosquito larvae). We also observed cannibalism among adult females. We found low fecundity and high mortality in females sampled from the crowded population and kept in low density laboratory conditions. We discuss how cannibalism, delayed egg hatching, fecundity loss and high mortality by crowding regulate high density populations of $\mathrm{H}$. incongruens, a typical $r$ strategy species.
\end{abstract}

Key words: temporary pond, swarms, resting eggs, risk-spreading

\section{INTRODUCTION}

The study of a species colonization of a temporary pond, even in its basic components (e.g., successful invasion of a new habitat, size of the established population, recruitment mechanisms) could be informative on the capacity to form patches of individuals and their ecological significance, on the trophic interaction among individuals of the same or of other species, on the mechanisms that lead to population crashes in $r$ strategy species. Temporary ponds and the micro crustacean based communities that they host are ideal for observational or experimental ecological studies (De Meester et al. 2005; Vanschoenwinkel \& Brendonck 2010). The combination of factors needed for successful recruitment may not materialize and time periods in which few or no species are present might not be uncommon.

The patchy distribution of zooplankton organisms is a major feature of many marine and freshwater habitats (Hutchinson 1967; Pinel-Alloul 1995; Folt \& Burns 1999). The timing and extent of either migration or swarming are affected by light levels, food resources, temperature and by all other factors that generate spatial patterns in zooplankton populations: physical-chemical, reproductive, social, coactive and stochastic processes (Hutchinson 1967; Lampert 1989). Recent studies suggest that behavioural interactions between organisms and physical or chemical features at fine scale may also be important in generating spatial patterns (Ambler
2002; Woodson \& McManus 2007). Proximity to mates, reduction of predation and maintenance of position in a favourable habitat have been proposed as possible advantages of swarming that may be the result of a trade-off with food availability since food concentrations may be lower in the inner portion of swarms (Loose \& Dawidowicz 1994).

Population dynamics of zooplankton may be patchy in space and time. They generally show the characteristics of $r$-selected species: small size, short generation time, and especially in parthenogenetic taxa, rapid population growth, opportunistic exploitation of pulse resources and high colonisation ability. Some of these organisms, e.g. Cladocera and Monogononta rotifers, reproduce by alternating asexual and sexual phases. Many have the capacity to produce resting eggs tolerant of harsh environmental conditions and crowding is one of the main factors inducing production of resting eggs (Guisande 1993; Snell et al. 2001; Timmermeyer \& Stelzer 2006). Dormant stages in the so called "egg bank" have the potential to buffer population fluctuation preventing local extinctions, causing reproduction synchronisation and reducing sibling competition (De Stasio 1989; Hairston 1998; Gyllstrom \& Hansson 2004).

Ostracods, the most diverse class of Crustacea, occupy all aquatic niches, from the deep sea to temporary ponds. Between 10,000 and 15,000 living species have been described, but the number more than doubles if fossil species are considered (Meisch 2000; Wilkinson et al. 2007; Martens et al. 2008). Shells are easily 
preserved in sediments and fossil ostracods are important stratigraphic and environmental indicators, with important applications in oil and gas exploration. Ostracods are a conspicuous component of the communities of temporary aquatic habitats and survive adverse periods as resting eggs (Meisch 2000). They may be freeswimming or, more commonly, benthonic, living under aquatic plants or crawling on or through the sediment and display a variety of feeding habits as filter-feeders, detritivores, herbivores and carnivores. Carnivory may take the form of predation, scavenging and parasitism (Vannier et al. 1998). Predation on larger animals is practiced by large and swimming marine genera (e.g., Gigantocypris and Vargula (Vannier et al. 1998; Wilkinson et al. 2007)). According to Wilkinson et al. (2007), in freshwater habitats, predation has been reported but not frequently. Cypridopsis hartwigi, $C$. vidua and Cypretta kawatai have been described as efficient predators of young Biomphalaria glabrata, the vector of schistosomiasis (Deschiens et al. 1953; Deschiens 1954; Sohn \& Kornicker 1972). Heterocypris incongruens preys on small organisms as Daphnia magna, Copepods, other Ostracods, Oligochaeta, Cladocera and insect larvae (Ganning 1971; Meisch 2000) and can be an active predator on amphibians (Ottonello \& Romano 2010). Scavengers are able to ingest massive quantities of dead or live particles that are collected using appendages shaped by selection (McLay 1978a; Meisch 2000; Wilkinson et al. 2007). Swarming is one of the characteristics of scavenging ostracods (Wilkinson et al. 2007). Swarms are attracted by various food sources and several hundred individuals have been recorded feeding on dead or dying animals. Fish, larvae of dragonflies and water mites are known to feed on freshwater ostracods (Meisch 2000). In marine habitats, nocturnal, migrating assemblages are dominated by crustaceans, including ostracods. Males of luminescent cypridinid ostracods use species specific complex and ritualized swimming patterns courtship displays to attract females (Rivers \& Morin 2009). Stepien \& Brusca (1985) showed that the luminescent ostracod $V$. tsujii may migrate primarily to feed, may attack in swarms relatively quiescent fishes and is attracted to injured individuals. Scarce information exists on behaviour, migration and swarm formation in freshwater species. The diurnal migration described by Benzie (1984) in a bisexual population of $H$. incongruens in a temporary pool in West Africa was explained as a response to oxygen reduction due to higher daylight temperature.

Here we report the colonization and population dynamics that followed the release of laboratory grown Heterocypris incongruens clonal organisms, in an Italian temporary pond where the species was not present in previous years. Laboratory observations suggest that swarm formation may lead to predatory behaviour and cannibalism. We suggest that cannibalism, delayed egg hatching and the effect of swarming on population dynamics parameters may contribute to density regulation.

\section{MATERIAL AND METHODS}

Heterocypris incongruens is a cosmopolitan common species inhabiting shallow seasonal pools and small water bodies (Meisch 2000). Fryer (1997) referred to this species as the "horse-trough ostracods" and reported that "individuals often congregate near surface, where oxygen is most plentiful, and lay many of their eggs". In seasonal pools it "often gather in masses around the very edge of the water, forming a conspicuous yellowish brown stripe" (Meisch 2000). Parthenogenetic populations occur nearly world wide and bisexual populations are known, from circum-Mediterranean area, central and eastern Europe. H. incongruens is omnivorous: its food consists of bacteria, algae, organic detritus, dead and living plant material and the body of invertebrates (Meisch 2000). Newborns and juveniles feed on faeces of the adults of their own species (Rossi, personal observation). Occasionally it has been observed attacking dead and living invertebrates such as cladocerans, copepods, chironomids, oligochaetes and other ostracods (Ganning 1971; Meisch 2000). H. incongruens is highly tolerant of temperature, salinity variations, low oxygen concentration and organic pollution (Mezquita et al. 1999; Meisch 2000). It is the most widespread species in Northern Italy where at least 125 different clonal lineages and seasonal succession of different ecotypes were described (Rossi et al. 2003; Rossi et al. 2006). The $\mathrm{W}$ type clonal lineage is the most common and widespread in the Northern Italian ricefields and temporary ponds (Rossi et al. 2006). It is a typical "winter ecotype" well adapted to the local continental highly seasonal conditions that fares better at low temperature. Its eggs hatch, although slowly, even at 4 ${ }^{\circ} \mathrm{C}$. In laboratory conditions, the $\mathrm{W}$ type clonal females, reared in one individual cultures, produced mostly (80$90 \%$ ) resting eggs at $24-28{ }^{\circ} \mathrm{C}$ and $16: 8 \mathrm{~L}: \mathrm{D}$ photoperiod and only $20-40 \%$ of those type of eggs at $16-24{ }^{\circ} \mathrm{C}$ and 12:12 L:D photoperiod (Rossi \& Menozzi 1990; 1993; Rossi et al. 1996).

\subsection{Field observation}

The first week of May 2009 five laboratory grown $\mathrm{W}$ type clonal females of $H$. incongruens were released in a temporary pond on the University of Parma Campus (445' $\mathrm{N} 10^{\circ} 39^{\prime} \mathrm{E}, 64 \mathrm{~m}$ a.s.l.). In sporadic samples taken from the pond in the previous 5 years, H. incongruens had never been found. At the time, the pond was approximately $17 \mathrm{~m}$ long, $9 \mathrm{~m}$ wide and $10-15 \mathrm{~cm}$ deep. The $\mathrm{W}$ clonal lineage we used was obtained from a single female from a ricefield (Budrione, 44 41' N $10^{\circ} 41^{\prime} \mathrm{E}$ ), genetically characterised by allozyme markers, and maintained in laboratory controlled conditions $\left(24{ }^{\circ} \mathrm{C}\right.$ and 12:12 LD photoperiod) for at least 10 generations (Gialdi, in preparation). Our field observation 

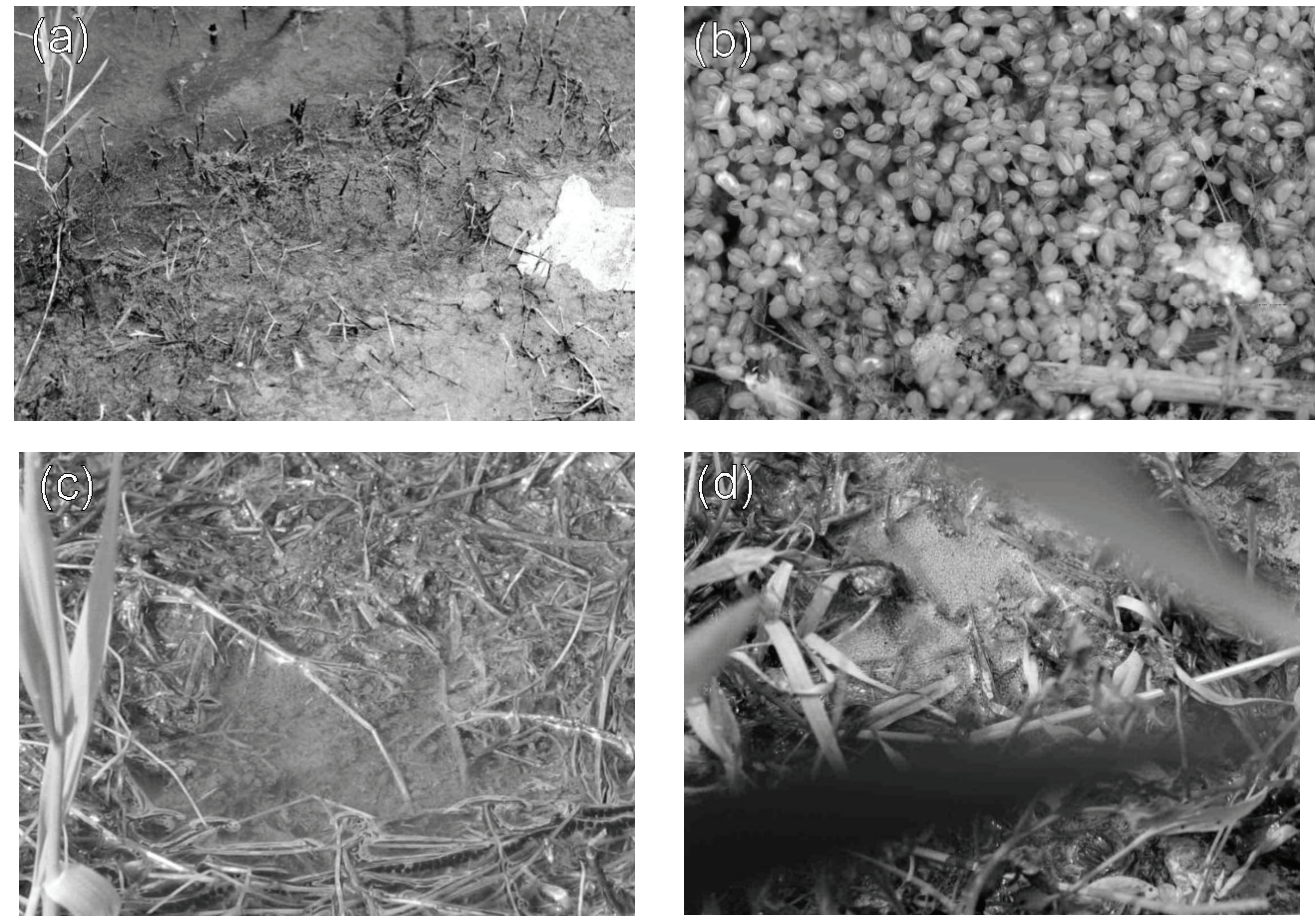

Fig. 1. Examples of migration and swarming of $H$. incongruens in Northern Italy temporary pond. a) Swarm formed by adult females on 19 June 2009 at 16:00 h. b) detail of adult female swarm. c) Swarm formed by pre adult females on 24 March 2010 at 09:00 h. d) Crowded population on 17 May 2010 at $14: 30 \mathrm{~h}$.

lasted for 13 months. Water level, H. incongruens presence, swarms formation and water oxygen saturation (Aqualytic Oxygen-meter) were recorded. At the end of our observation we checked the clonal genetic structure of the population according to Rossi et al. (2006). Swarm formation, swarm and population densities were documented and estimated from photographic images using a Nikon D80 with a Nikkor 18-200 mm f/3.5-5.6 VR lens (for panoramic photos) or Tamron 90 F2.8 (for macro).

\subsection{Laboratory observations}

$H$. incongruens behaviour in high density was documented in the laboratory by video recording of several trials that were set up in Petri dishes $(8 \mathrm{~cm}$ diameter, in $20 \mathrm{~mL}$ of pond water). In the first experiment, ten trials were designed to estimate predation of $H$. incongruens. Each Petri dish contained one hundred clonal females. One live chironomid larva (about $1.5 \mathrm{~cm}$ long, 10 times the mean size of an adult $H$. incongruens female) was added to three dishes. The remaining seven contained three live mosquito larvae. In the second experiment, ten trials were set up to observe cannibalism. Each Petri dish contained ten clonal females.

In July 2009 and at the end of May 2010 when the pond was drying up, adult females were sampled to observe egg-hatching phenology. Each female was reared in a single well of cell culture plate, in $2.5 \mathrm{~mL}$ of commercial high Calcium bottled mineral water and fed ad libitum Tolypothrix tenuis (Cyanobacteria). Females were kept on the laboratory windowsill to match natural photoperiod and temperature: survivorship and egg hatching phenology were recorded for at least 150 days. Laboratory observations were carried out and recorded using a stereomicroscope Nikon SNZ-2T with a Panasonic Digital with TV lens C- $0.45 \times$.

\section{RESULTS}

\subsection{Field observations}

In 2009 water was present (hydroperiod) from 25 April to 15 July. Air temperature ranged from 8.7 (on April 24) to $36.9^{\circ} \mathrm{C}$ (on May 25), mean air temperature was $22.8^{\circ} \mathrm{C}$ and daylength ranged from 13:59 and 15:16 hours. Since $H$. incongruens had not been found in the pond in previous years, it is reasonable to assume that the starting population was made up of the five $\mathrm{W}$ individuals released at the beginning of the hydroperiod. After 45 days, the pond harboured a large H. incongruens population made up by adult ovigerous females (about $1.4 \mathrm{~mm}$ in size). We estimated the population size at 30,000 - 100,000 individuals. High densities and orange clusters were observed within $10 \mathrm{~cm}$ of pool edge (Fig. 1a). By the analysis of 6 photos we estimated the clusters' density: $70.7( \pm 3.82)$ ind $\mathrm{cm}^{-2}$ (that is about 1600 ind $\mathrm{cm}^{-3}$ ) (Fig. 1b). Observation over several days indicated that clustering was present between midday and $4 \mathrm{pm}$. No aggregations were observed outside this time interval. No oxygen gradient was measured between the middle and the edges of the pool and water was oxygen-saturated throughout the pool. In the first 

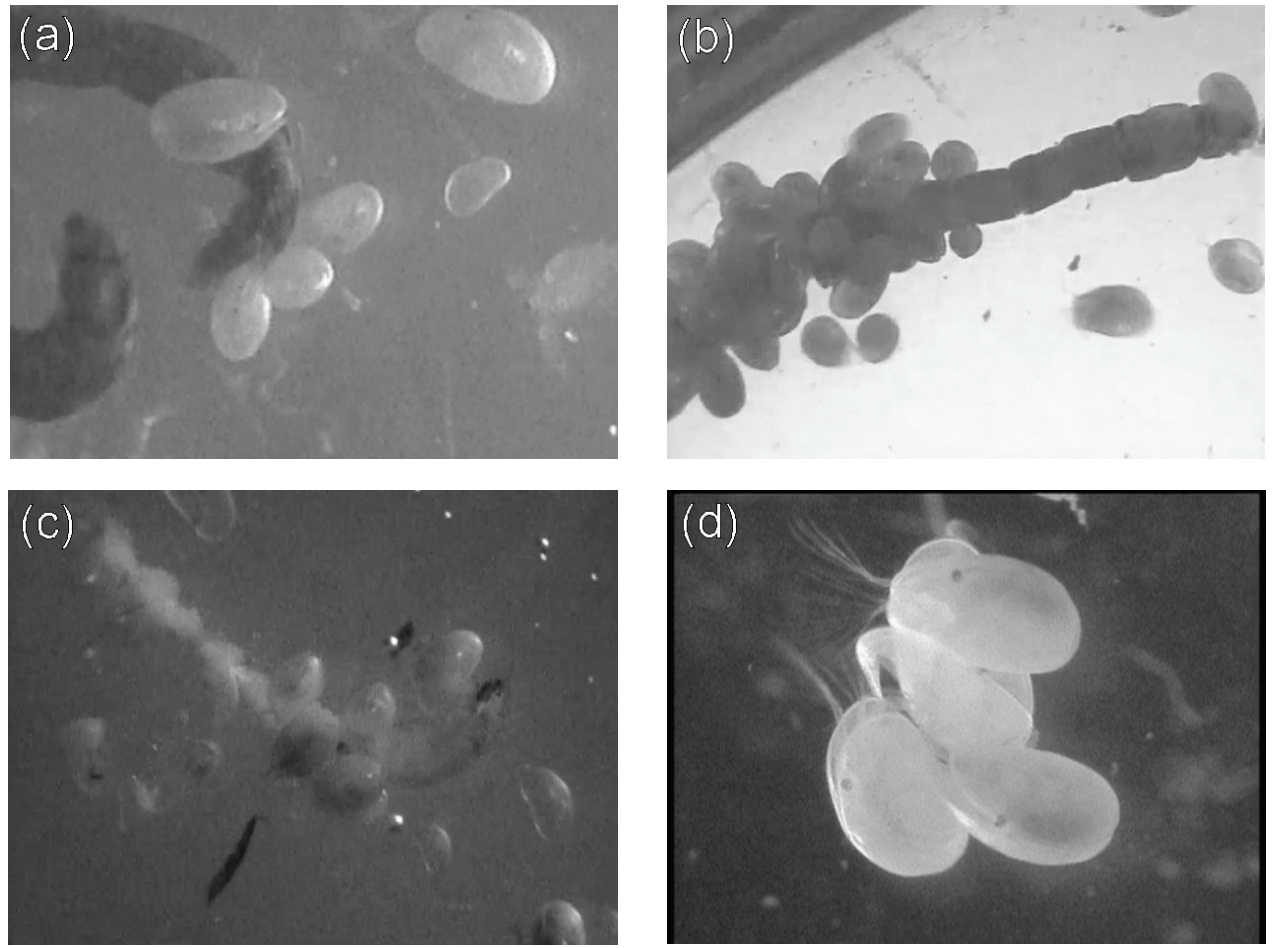

Fig. 2. In these frames predation on live chironomid larva and on conspecific by $H$. incongruens females are documented. a) Few adult females began the attack biting at the mouth and anus of the larva. b) A swarm is formed and the larva is rapidly surrounded. c) The larva is entirely consumed d) In a successful attack among $H$. incongruens females the victim's soft body parts are consumed and empty valves are left.

half of July 2009 the pond dried up and did not fill again until February 2010. On June 18, 72 adult females were sampled and used for laboratory observation. They produced resting and non resting eggs. We are unable to quantify the former as they were in patches of eggs numbering in the tens for females. A total of 211 eggs hatched during the 150-day observation in the laboratory: 7 eggs (3\%) hatched within 7-30 days from deposition, the remaining hatched gradually starting around 60 days with a peak around 90 days when 111 eggs $(53 \%)$ hatched. Net growth rate was 2.93 (hatchlings per female).

In the second hydroperiod (24 February - 26 March 2010) air temperature ranged from $-8.0^{\circ} \mathrm{C}$ (on March 10) to 19.1 (on March 24), mean air temperature was $8.2{ }^{\circ} \mathrm{C}$ and daylength ranged from 10:45 to $12: 25$ hours. The 2010 population recruited from resting eggs produced in summer 2009. We estimated a population size of 14,700 individuals. On March 24 clustering was observed around 9 a.m. (Fig. 1c). Water was oxygensaturated and no oxygen gradient was observed. In this case orange swarms were made up of pre adult females that could not reach sexual maturity since the pond had dried up by March 26.

The pond filled again on May 5 2010. The pond size was smaller than in spring 2009: $4 \mathrm{~m}$ long, $3 \mathrm{~m}$ wide and less then $15 \mathrm{~cm}$ deep. H. incongruens population recruited from the hatching of resting eggs produced in summer 2009 that had not hatched in February 2010 and reached high density (Fig. 1d). We estimated a popula- tion size of 416,000 individuals. In this third hydroperiod, given the smaller pond size, it was difficult to distinguish swarms in a high density population. Juveniles were generally visible to the eye by May 12. Adult females appeared in few days later but apparently they did not lay any eggs before the pond dry up on May 30 . During this third hydroperiod air temperature ranged from 10.3 (on May 7) to $32.0^{\circ} \mathrm{C}$ (on May 24), mean air temperature was 17.8 and daylength ranged from 14:15 and 15:19 hours. On May 25, 95 adult females were transferred into the laboratory: they died within 10 days and laid a total of only 8 eggs that did not hatch within 30 days.

On the basis of a genetic analysis we can exclude that any resting eggs of the wild $H$. incongruens clonal lineages different from the $\mathrm{W}$ type dispersed into the pond.

\subsection{Laboratory observations}

Under laboratory conditions, group predation on a live chironomid larvae and small mosquito larvae were observed in all ten trials that we have carried out. In figure $2 \mathrm{a}$, four-five adult females began to attack biting at the mouth and anus of the chironomid larva. As a reaction, the prey showed sudden movements but a swarm was formed. The larva was rapidly surrounded by at least 50-60 ostracods (Fig. 2b). The release of body fluids made the larva to become progressively paler and probably attracted more ostracodes. It took about two hours to consume the entire larva (Fig. 2c). A very similar sequence was observed on live mosquito larvae. 
A video is available on http://www.dsa.unipr.it/ valeriarossi/predazione.avi.

$H$. incongruens had also a cannibalistic behaviour, although adult females tended to avoid conspecifics showing aggressive behaviour. Both single and group attack among adult females were observed in all ten trials we carried out. At first, the approach was generally cautious; then the attacker became more and more aggressive, especially when the victim appeared submissive, or did not retreat. In successful attacks the victim's soft body parts may be consumed and all was left were empty valves. It took about 15 minutes to kill and to eviscerate the victim (Figure 2d). A video is available on http://www.dsa.unipr.it/valeriarossi/cannibalismo.avi.

\section{DISCUSSION}

The successful invasion and establishment of a previously absent species was described and valuable new information was obtained from observations on the basic components of colonization of a temporary pond by a clonal lineage of Heterocypris inconguens. High population density was reached in a few weeks only and the abundance we have estimated in the field was compatible with net growth rate calculated from the laboratory rearings (19.9) (Cominelli et al. in preparation). Hydroperiod was a function of local rainfall and varied greatly within the same year and from year to year: it represents a constrain that affects density, resource availability and the duration of population increase. The production of resting eggs enables the population to survive desiccation allowing the population to recruit (Hairston et al. 2000; Spencer et al. 2001). Not all resting eggs produced in early summer 2009 (we estimated a production of $600,000-2,000,000$ resting eggs that is 20 resting eggs by $30,000-100,000$ females) hatched in the second hydroperiod in winter 2010 (that is after their first hydration). In winter 2010 water was too cold and did not last long enough to allow females to mature and lay eggs. The highest density population we observed in May 2010 could only have been recruited from resting eggs produced in 2009 that did not hatch in the first rehydration episode of winter 2010. The spread of the hatching of resting egg of a single genotype over more than one hydration episode represents a first step in the setting up of a clonal egg bank (Rossi et al. 2004; Albini et al., in preparation). Interesting aspects of dormancy, such as risk reduction connected to environmental unpredictability and sibling competition and buffering local population extinction have been emphasized in the literature (De Stasio 1989; Hairston et al. 1996; Hairston 1998; Gyllstrom \& Hansson 2004). It is important to note that, in our case, all these aspects were referred to a clonal population and the spread of the hatching of resting egg of a single genotype represent a genuine diversified bet-hedging strategy that enhances the performance of a clonal lineage in changing environments by diversified risk-spreading (Seger \&
Brockmann 1987; Simovich \& Hathaway 1997; Crean \& Marshall 2009). As well, the spread of hatching over time of non resting eggs produced in summer 2009 and maintained hydrated in the laboratory for 150 days should represent a bet-hedging strategy to control population density and reduce sib competition (McLay 1978b, c; Angel \& Hancock 1989; Rossi et al., in preparation).

In the $\mathrm{W}$ type clonal lineage we have shown that long daylight is a crucial cue in inducing resting egg production (Rossi et al. 1993). Under laboratory conditions $\left(24{ }^{\circ} \mathrm{C}\right.$ temperature and 12:12 L:D photoperiod) we observed that the $\mathrm{W}$ type clonal lineage net growth rate decreases from 19.9 to 3.7 with increasing density from 0.51 to 2.5 ind $\mathrm{mL}^{-1}$ and that percentage of resting eggs is not affected by these population densities (Cominelli et al. in preparation). On the other hand, we have observed that, in crowded population (late spring 2010), fecundity decreased dramatically and did not recover even in the laboratory where conditions were suitable for reproduction. Mass mortality and failed fecundity was caused by drying and/or crowding and further investigation are needed to evaluate the actual role of density dependence in $H$. incongruens.

Benzie (1984) reported diurnal migration of $H$. incongruens from a muddy to a rocky benthic substrate in a small pool in Northern Guinean savanna (Ghana) $\left(9^{\circ} 11^{\prime} \mathrm{N}, 2^{\circ} 20^{\prime} \mathrm{W}\right)$. His "dark brown clusters" are very similar to the groups of individuals that formed every day in our pool. Development stages were also similar: in Benzie's bisexual population, clusters were made up by males, females and juveniles, in our parthenogenetic population pre adults dominated the late winter population and adult females were abundant in late spring early summer. Our estimation of cluster density was not significantly different from that of Benzie $(57.4( \pm 17.6)$ ind $\left.\mathrm{cm}^{-2}\right)$ reported at $11 \mathrm{am}(t$-Student test $=0.791$, gdl $=14, p<0.025)$. Benzie (1984) suggests that organisms migrate to avoid the reduction in oxygen associated with higher mid-day temperatures. In our pool oxygen gradients were not present either among locations (e.g., center and edges) or time during the day. Moreover $H$. incongruens is tolerant of low oxygen contents (Green 1959; Meisch 2000). We could not find a simple single cause for the observed daily forming of swarms. In our parthenogenetic population we can exclude mating behaviour. In the cyclical parthenogen Daphnia longispina, Young et al. (1994) found that most individuals in a swarm belonged to the same clone and hypothesized that clones may form "unselfish swarms" which benefit the individual and the group. We observed swarm forming in different seasons with or without predators. This would justify excluding that swarms are an antipredator strategy. Migration and swarming have been observed around noon in different seasons, at different latitudes. In our late winter observation the morning occurrence could be seen happening around the median time of the sun path. We assume that sun path 
and/or endogenous rhythmicity may be involved in these phenomena (Enright \& Hamner 1967; Ringelberg 1995; Graham et al. 2001; Cottier et al. 2006; Kao et al. 2010).

We cannot exclude that both pre-adult and adult females were attracted by various food sources and, our laboratory observations suggest a role of swarms in group predation. Ostracod swarms on lager animals have been reported in freshwater lakes although actual predation has not been observed (Wilkinson et al. 2007). Sohn \& Kornicker (1972) showed that the rate of predation is controlled by the ostracod density and suggested to use ostracods as biological control of trematode disease owing to their significant predatory rate on vector snails. Stepien \& Brusca (1985) showed that the luminescent ostracods $V$. tsujii migrate to feed, attack in swarms relatively quiescent fishes and are most strongly attracted to injured individuals. But, Ottonello \& Romano (2010) also reported that $H$. incongruens is able to behave as an active predator on amphibians and showed swarms on Bufo bufo egg strings. Our laboratory observation on $H$. incongruens behaviour is very similar to the predation by the very different marine species Vargula hilgendorfii on live polychaetes (Vannier et al. 1998). From our videos it is clear that $H$. incongruens females attack their prey, that if prey blood or if liquid contents are released into the water attracting more individuals, that swarm causes prey death and consumation.

In the laboratory we documented cannibalism in $H$. incongruens clonal females. This phenomenon was described in Eucypris virens (Kiefer 1936 see Wilkinson et al. 2007) and we have observed cannibalism of eggs by Heterocypris males (non published data). Cannibalism is widespread in animal species: net energy gain is a crucial component of cannibalism although theoretical work did not demonstrate that food limitations are a necessary condition for its evolution (Volker et al. 2010). Ecologists have recognised cannibalism as a density dependent mechanism having two main effects: to stabilize population numbers and to reduce sib competition (Hopper et al. 1996). Elevated density both increases encountered probability between conspecifics and reduces per capital food availability. In the copepod Centropages typicus, crowding does not affect spawning behaviour when population densities are close to field conditions but overcrowding induced by swarming or aggregation may potentially limit reproductive success owing to cannibalism of eggs (Miralto et al. 1996). Cannibalism rates have been shown to vary directly with population density and can contribute to population regulation by imposing greater mortality at high densities. Cannibalism removes potential competitors, and selective filial cannibalism may also decrease density-dependent mortality in offspring (Klug $\&$ Bonsall 2007). Among the costs of cannibalism, if it involves the consumption of genetically related individuals, are losses in inclusive fitness. Cannibalism among genetically identical organisms seems an interesting case study.

We suggest that cannibalism, bet-hedging strategy in eggs hatching phenology, and a fecundity control by soft temporary crowding (swarming) could contribute to regulate population density in a typical $r$ strategy opportunistic species such as $H$. incongruens (JuarezFranco et al. 2009). In conclusion, this means that ostracod abundance and assemblages should not only be controlled by abiotic factors and this might have important implication either for evolutionary biologists and palaeontologists.

\section{ACKNOWLEDGEMENTS}

We wish to thank Dania Albini, Simone Cominelli and Sandro Gialdi for their help with laboratory experiments. We thank Claude Meisch and two anonymous reviewers for critical comments and helpful suggestions. This study was financially supported by FIL 2007 and PRIN 2007.

\section{REFERENCES}

Ambler, J.W. 2002. Zooplankton swarms: characteristics, proximal cues and proposed advantage. Hydrobiologia, 480: $155-164$.

Angell, R.W. \& J.W. Hancock. 1989. Response of eggs of Heterocypris incongruens (Ostracoda) to experimental stress. J. Crustac. Biol., 9: 381-386.

Benzie, J.A.H. 1984. Small scale diurnal migrations by Heterocypris incongruens (Ramdohr, 1808) (Ostracoda: Cyprididae) in a temporary pool, Ghana, West Africa. $J$. Crustac. Biol., 4: 63-65.

Cottier, F.R., G.A.Tarling, A. Wold \& S. Falk-Petersen. 2006. Unsynchronized and synchronized vertical migration of zooplankton in a high arctic fjord. Limnol. Oceanogr., 51: 2586-2599.

Crean, A.J. \& D.J. Marshall. 2009. Coping with environmental uncertainty: dynamic bet hedging as a maternal effect. Phil. Trans. R. Soc. B, 364: 1087-1096.

De Meester, L., Declerck, S., Stoks, R., Louette, G., Van De Meutter, F., De Bie, T., Michels E. \& L. Brendonck. 2005. Ponds and pools as model systems in conservation biology, ecology and evolutionary biology. Aquatic Conserv: Mar. Freshw. Ecosyst., 15: 715-725.

De Stasio, B.T. Jr. 1989. The seed bank of a freshwater crustacean: copepodology for the plant ecologist. Ecology, 70: 1377-1389.

Deschiens, R. 1954. Mécanisme de l'action léthale de Cypridopsis hartwigi sur les mollusques vecteurs des bilharzioses. Bull. Soc. Pathol. Exot., 47: 399-401.

Deschiens, R., L. Lamy \& H. Lamy. 1953. Sur un ostracode prédateur de Bullins et de Planorbes. Bull. Soc. Pathol. Exot., 46: 956-958.

Enright, J.T. \& W.M. Hamner. 1967. Vertical diurnal migration and endogenous rhythmicity. Science, 157: 937-941.

Folt, C.L. \& C.W. Burns. 1999. Biological drivers of zooplankton patchiness. Trends Ecol. Evol., 14: 300-305.

Fryer, G. 1997. The horse-trough ostracod Heterocypris incongruens. The Naturalist, 122: 121-135.

Ganning, B. 1971. On the ecology of Heterocypris salinus, $H$. incongruens and Cypridopsis aculeata (Crustacea, Ostracoda) from Baltic brackish-water rockpools. Mar. Biol., 8: 271-279.

Graham, W.M., F. Pages \& W.M. Hamner. 2001. A physical context for gelatinous zooplankton aggregations: a review. Hydrobiologia, 451: 199-212. 
Green, J. 1959. Pigmentation of an ostracod, Heterocypris incongruens. J. Exp. Biol., 36: 575-582.

Guisande, C. 1993. Reproductive strategy as population density varies in Daphnia magna (Cladocera). Freshwat. Biol., 29: 463-467.

Gyllstrom, M.L. \& A. Hansson. 2004. Dormancy in freshwater zooplankton: Induction, termination and the importance of benthic-pelagic coupling. Aquat. Sci., 66: 274-295.

Hairston, N.G. Jr. 1998. Time travels: what's timely in diapause research? Arch. Hydrobiol. Spec. Issues Advanc. Limnol., 52: 1-15.

Hairston, N.G. Jr, A.M. Hansen \& W.R. Schaffner. 2000. The effect of diapause emergence on the seasonal dynamics of a zooplankton assemblage. Freshwat. Biol., 45: 133-145.

Hopper, K.R., P.H. Crowley \& D. Kielman. 1996. Density dependence, hatching synchrony, and within cohort cannibalism in young dragonfly larvae. Ecology, 77: 191-200.

Hutchinson, G.E. 1967. A Treatise on Limnology, Vol. II: Introduction to lake biology and the limnoplankton. Wiley, New York: pp 1048.

Juarez-Franco, M.F., S.S.S. Sarma \& S. Nandini. 2009. Population dynamics of Heterocypris incongruens (Ramdohr, 1808) (Ostracoda, Cyprididae) in relation to diet type (algae and organic waste) and amount of food. Crustaceana, 82: 743-752.

Kao, C.C., J. Chen, G.F. Chen \& K. Soong. 2010. Variable swarming time of an intertidal midge (Pontomyia oceana Tokunaga, 1964) controlled by a circadian clock and temperature. Mar. Freshwat. Behav. Physiol., 43:1-9.

Klug, H. \& M.B. Bonsall. 2007. When to care for, abandon, or eat your offspring: the evolution of parental care and filial cannibalism. Am. Nat., 170: 886-901.

Lampert, W. 1989. The adaptive significance of diel vertical migration of zooplankton. Funct. Ecol., 3: 21-27.

Loose, C.J. \& P. Dawidowicz. 1994 Trade-offs in diel vertical migration by zooplankton: the cost of predator avoidance. Ecology, 75: 2255-2263.

Martens, K., I. Schoen, C. Meisch \& D.J. Horne. 2008. Global diversity of Ostracods (Ostracoda, Crustacea) in freshwater. Hydrobiologia, 595:185-193.

McLay, C.L. 1978a. Comparative observation on the ecology of four species of ostracods living in a temporary freshwater puddle. Can. J. Zool., 56: 663-675.

McLay, C.L. 1978b. The population biology of Cyprinotus carolinensis and Herpetocypris reptans (Crustacea: Ostracoda). Can. J. Zool., 56: 1170-1179.

McLay, C.L. 1978c. Competition, coexistence, and survival: a computer simulation study of ostracods living in a temporary puddle. Can. J. Zool., 56: 1744-1758.

Meisch, C. 2000. Freshwater Ostracoda of Western and Central Europe. Spektrum Akademischer Verlag, Heidelberg, Berlin: pp 522.

Mezquita, F., H.I. Griffiths, S. Sanz, J.M. Soria \& A. Pinon. 1999. Ecology and distribution of ostracods associated with flowing waters in the Eastern Iberian. J. Crustac. Biol., 19: 344-354.

Miralto, A., A. Ianora, S.A. Poulet, G. Romano \& M. Laabir. 1996. Is fecundity modified by crowding in the copepod Centropages typicus? J. Plankton Res., 18: 10331040.

Ottonello, D. \& A. Romano. 2010. Ostracoda and Amphibia in temporary ponds: who is the prey? Unexpected trophic relation in a Mediterranean freshwater habitat. Aquat. Ecol., DOI 10.1007/s10452-010-9323-y

Pinel-Alloul, B. 1995. Spatial heterogeneity as a multiscale characteristics of zooplankton community. Hydrobiologia, 300/301: 17-42.

Received: October 2010

Accepted: December 2010
Ringelberg, J. 1995. Changes in light intensity and diel vertical migration - a comparison of marine and fresh-water environments. J. Mar. Biol. Assoc. UK, 75:15-25.

Rivers, T.J. \& J.G. Morin. 2009. Plasticity of male mating behaviour in a marine bioluminescent ostracod in both time and space. Anim. Behav., 78: 723-734.

Rossi, V. \& P. Menozzi. 1990. The clonal ecology of Heterocypris incongruens (Crustacea, Ostracoda). Oikos, 57: 388-398.

Rossi, V. \& P. Menozzi. 1993. The clonal ecology of Heterocypris incongruens (Ostracoda): life-history traits and photoperiod. Funct. Ecol., 7: 177-182.

Rossi, V., A. Gandolfi \& P. Menozzi. 1996. Egg diapause and clonal structure in parthenogenetic population of Heterocypris incongruens (Ostracoda). Hydrobiologia, 320: 45-54.

Rossi, V., G. Benassi, S. Leonardi, A. Piotti \& P. Menozzi. 2006. Clonal diversity of Heterocypris incongruens (Crustacea: Ostracoda) in Northern Italian ricefields. Arch. Hydrobiol., 166: 225-240.

Rossi, V., M. Bartoli, C. Bellavere, A. Gandolfi, E. Salvador \& P. Menozzi. 2004. Heterocypris (Crustacea: Ostracoda) from the Isole Pelagie (Sicily, Italy): hatching phenology of resting eggs. Ital. J. Zool., 71: 223-231.

Rossi, V., G. Benassi, M. Veneri, C. Bellavere, P. Menozzi, A. Moroni \& K.G. McKenzie. 2003. Ostracoda of the Italian ricefields thirty years on: new synthesis and hypothesis. $J$. Limnol., 62: 1-8.

Seger, J. \& H.J. Brockmann. 1987. What is bet-hedging? In: P.H. Harvey \& L. Partrige (Eds), Oxford surveys in evolutionary biology. Vol 4. Oxford University Press, Oxford: 182-211.

Simovich, M.A. \& S.A. Hathaway. 1997. Diversified bethedging as a reproductive strategy of some ephemeral pool Anostracans (Branchiopoda). J. Crustac. Biol., 17: 38-44.

Snell, T.W., B.J. Dingmann \& M. Serra. 2001. Density-dependent regulation of natural and laboratory rotifer populations. Hydrobiologia, 446-447: 39-44.

Sohn, I.G. \& L.S. Kornicker. 1972. Predation of schistosomiasis vector snails by Ostracoda (Crustacea). Science, 175: 1258-1259.

Spencer, M., N. Colegrave \& S.S. Schwartz. 2001. Hatching fraction and timing of resting stage production in seasonal environments: effects of density dependence and uncertain season length. J. Evol. Biol., 14: 357-367.

Stepien, C.A. \& R.C. Brusca. 1985. Nocturnal attacks on nearshore fishes in southern California by crustacean zooplankton. Mar. Ecol. Progr. Ser., 25: 91-105.

Timmermeyer, N. \& C.P. Stelzer. 2006. Chemical induction of mixis in the rotifer Synchaeta tremula. J. Plankton Res., 28: $1233-1239$.

Vannier, J., K. Abe \& K. Ikuta. 1998. Feeding in myodocope ostracods: functional morphology and laboratory observations from videos. Mar. Biol., 132: 391-408.

Vanschoenwinkel, J.M.B. \& L. Brendonck. 2010. Anostracan monopolisation of early successional phases in temporary waters? Fundam. Appl. Limnol., 176: 127-132.

Volker, H.W.R., M. Kamo \& M. Boots. 2010. Cannibals in space: the coevolution of cannibalism and dispersal in spatially structured populations. Am. Nat., 175: 513-524.

Wilkinson, I.P., P.R. Wilby, M. Williams, D.J. Siveter \& J. Vannier. 2007. Ostracod carnivory through time. In: A.M.T. Elewa (Ed.), Predation in organisms: a distinct phenomenon. Springer Berlin, Heidelberg: 39-57.

Woodson, C.B. \& M.A. McManus. 2007. Foraging behaviour can influence dispersal of marine organisms. Limnol. Oceanogr., 52: 2701-2709.

Young, S., P.J. Watt, J.P. Grover \& D. Thomas. 1994. The unselfish swarm? J. Anim. Ecol., 63: 611-618. 